\title{
Impact of Agriculture on Groundwater: Sri Lankan Perspective
}

\author{
D.S.P. Kuruppuarachchi
}

\section{Agriculture as an Environmental Pressure}

Cultivation of crops for food production and for economic benefit, and husbandry of livestock have for long been dominant activities in human communities. Population growth and increasing living standards and the associated demand for food production are the driving forces for expansion and intensification of agriculture of the world's total land area of 13 billion hectares. The scope for meeting the growing demand for food by increasing the amount of agricultural land at the expense of forests and natural savannah is limited - most suitable land is already used. Demand is therefore largely met by increasing the productivity of existing cultivated land. Irrigation must continue to play its part in this by enabling new crops to be grown where they could not previously and by extending the growing season and cropping intensity on already cultivated land.

\section{Irrigation, Waterlogging and Salinity}

Potable water resources are mainly identified as surface water or groundwater. Unlike surface water bodies such as rivers, lakes and tanks which are usually exposed to human activity, groundwater is less affected as it is held underground. The dramatic growth in irrigated agriculture and consequent demand for water is also met by diverting and/or storing surface water.

Food and Agriculture Organization Representation in Sri Lanka,

202, Bauddhaloka Mawatha,

Colombo 7

premalal.kuruppuarachchi@gmail.com
However, withdrawing water from rivers to spread on land accelerates the accumulation of salts through evaporation. Moreover, the excess infiltration from the irrigated land causes the underlying groundwater levels to rise, sometimes by many meters, producing water logging in poorly drained soils where the groundwater level comes close to the ground surface. When the groundwater is within a meter or two of the land surface, capillary action allows water to rise further and evaporate from the land surface, resulting in salinization of soils and water. Overall assessment of the extent and severity of the impacts of salinization is not easy.

\section{Use of Groundwater}

In Sri Lanka, almost $80 \%$ of the rural population depend on groundwater resources for their day-to-day needs which include drinking and sanitation needs. It is also a vital source of water supply to hundreds of farmers and cultivators who depend on groundwater from agro-wells scattered across the island. Considering the significance of this gift of nature, it is surprising that little attention has been paid on the risk of exhaustion and contamination of ground water sources. Small farmers particularly in the areas of north central and north western provinces use large diameter agro-wells. In coastal sand aquifer areas like the Kalpitiya peninsula in the North West and Nilaweli in the east coast, there has been intensive use of the shallow groundwater for agriculture during the last three decades. 


\section{Over-Use and Depletion}

Groundwater pumping, a savior of dry zone cultivators in Sri Lanka, is the primary cause of groundwater depletion. This in turn can lower the water table where the well is no longer able to reach groundwater. As the water table lowers, pumps must reach lower levels consuming more power and thereby incurring more cost. Little known is the fact that surface water will not exist without groundwater. Depletion of groundwater tables will threaten the water supply to surface water resources such as rivers and lakes. Ultimately over pumping also threatens to collapse layers of soil causing what is known as land subsidence.

\section{Threats of Contamination}

Some aquifers in Sri Lanka are already contaminated with harmful chemicals in intensely cultivated areas. An aquifer is an underground layer of permeable rock, sediment or soil that yields water. The pore spaces in aquifers are filled with water and are interconnected, so that water flows through them. This means that sandstone, unconsolidated gravel and porous limestone make the best aquifers.

Together with irrigation, the large increases in food production have been sustained only by the application of everincreasing amounts of inorganic fertilizers and a wide spectrum of synthetic pesticides. While the rate of increase of fertilizer use is leveling off in the industrialized countries, rates of nitrogen fertilizer use have tripled in developing countries since 1975.

\section{Nitrate}

Fertilizers are used to increase the availability to plants of the nutrients nitrogen, phosphorus and potassium. Of these, potassium and phosphate are rarely leached below the soil and seldom found at elevated concentrations in groundwater because of they are often the lesser components in fertilizer mixtures and because phosphate is normally retained by adsorption onto clays in the soil. Nitrate is the principal nutrient leached to groundwater and is highly soluble, mobile and not readily degraded under aerobic conditions. Where Muriate of Potash $(\mathrm{KCl})$ is an important component of the fertilizer, elevated concentrations of chloride have also been observed in groundwater.

The risk of groundwater pollution by nitrate depends on the interaction of the nitrogen loading and the vulnerability of the aquifer. The term 'vulnerability' can be defined as "the intrinsic properties of the strata separating a saturated aquifer from the land surface which determine the sensitivity of that aquifer to being adversely affected by pollution loads applied at the surface.

In Sri Lanka, researchers have uncovered that the concentration of $\mathrm{N}$ has greatly increased particularly in ground water, the key reason being the application of heavy doses of nitrogenous fertilizers. Studies in coastal sand aquifers revealed that the buildup of nitrate was quite dramatic and estimated at $1-2 \mathrm{mg}-\mathrm{N}^{-1}$ per annum which is certainly unacceptable both in terms of water quality deterioration and waste of valuable crop nutrients. As groundwater is the main or probably the only source of potable water in aquifers where intensive agriculture is practiced, health implications associated with high intake of nitrate should be considered seriously and appropriate management plans should be implemented in order to enhance the sustainable and efficient use of groundwater resource. Agriculture in many developing countries including Sri Lanka is increasingly dependent on chemicals, mainly due to cost and yield concerns in 
organic cultivation. As the land available for crop production and water for irrigation is meanwhile becoming increasingly limited, increased food production to meet the demands must use the intensive agricultural practices. As in many areas, intensive crop production occurs on soils directly overlying shallow aquifers, the threat to groundwater quality and the risk to potable supplies are growing mainly due to the intensification of irrigated agriculture and accompanying increased use of fertilizers and pesticides.

\section{Pesticides}

All pesticides have the potential to pose a health hazard because they are chemically designed to be toxic and persistent enough to control weeds, insects and fungal pests. Prior to the early 1980s, little thought was given to the possibility of groundwater pollution by pesticides, since agricultural scientists believed they would be attenuated either by sorption or degradation in the soil or by volatilization. However, growing awareness of the processes of nitrate leaching, and the rapid increase in pesticide usage led to greater concern that pesticide residues could reach groundwater at problematic concentrations. Pesticide usage is concentrated on a small number of crops; rice, vegetables, maize, soybean, plantation crops, sugarcane, coffee, cocoa, pineapple, banana and oil palm. Application rates are usually in the range of 0.2 to 2.0 $\mathrm{kg} / \mathrm{ha}$ of active ingredient of product per two seasons of the year. Usage on vegetables in particular is becoming more widespread, often with the highest application rates. As for nitrate, the risk of pollution of groundwater depends on the interaction between pollutant load and vulnerability - the capacity to attenuate pesticides along the pathway through the soil and underlying aquifer. Again, as for nitrate, the mode of application is important. Soil-applied pesticides are more likely to be leached than leaf acting compounds sprayed onto the plants. The most important attenuation processes for pesticides - sorption, volatilization and degradation are most active in the soil, with its high content of clay and organic matter and active microbial populations. Once below the soil, the very small proportion of the applied pesticide that does leach is likely to be more mobile and persistent; the attenuation processes, although still present, being much less active. In the saturated zone, dilution will be the main attenuation mechanism which will help to limit the concentrations of pesticides in groundwater arriving at wells or boreholes.

\section{Investigating and Monitoring Agricultural Impacts on Groundwater Resources}

Investigating the potential impacts of agricultural water usage requires a sound conceptual model of the groundwater flow system, including sources and locations of natural and induced or imposed recharge and discharge. The former could include surface water in rivers, canals, irrigated land and drainage channels. Quantifying recharge from all sources is notoriously difficult and needs detailed investigation. Determining the total abstraction for all uses is also difficult, but this needs to be done so that the balance of resources between replenishment and abstraction can be estimated. Monitoring of the impacts of agricultural abstraction and the effectiveness of measures to control abstraction, alleviate the impacts or restore conditions requires the regular measurement of groundwater levels. Long term declines in levels are the best indication of heavy groundwater usage. 


\section{Unregulated Agro-Wells}

Even without the drought threatening the island the supply of water has constantly been a problem for the intermediate and dry zones of Sri Lanka. It is established that $90 \%$ of these zones are on hard-rock aquifers, where agro-wells have been installed. However, the lack of guidance and unawareness has resulted in a spring of unauthorized agro-wells. At present, a farmer can (at free will) exploit his private land and use a resource of water that is in fact a resource belonging to all. When reviewing the use of groundwater resource, it is apparent that development of agrowells has taken place in a rather haphazard and chaotic manner. However, in order to rectify this situation, discussions have been initiated by Sri Lankan Government to address the issue of unregulated digging of agro-wells. According to the gazette issued on March $15^{\text {th }}$, under the Water Resources Board (WRB) Act. 29 of 1964, any individual, government or private institute seeking to utilize natural water springs or groundwater for any purpose or project, should obtain written permission from the WRB and it should be carried out under its supervision. 